\title{
Media, Children and Play: \\ New Practices in a New (and Complex) Ecosystem
}

\author{
Carolina Duek ${ }^{1}$ \\ CONICET/University of Buenos Aires, Argentina
}

\section{doi:10.5937/comman1329103D}

Summary: The relationship between media and play has been the subject of my research during the last ten years. Along that period, the research has obtained a common conclusion: children are related to media as consumers, as audiences, as producers and as reproducers of what is shown on them. From the moment in which children are born a new ecosystem composed by different screens and devices becomes their home. I argue that play is a key dimension to analyze contemporary childhoods and their relationship to media culture. When children talk about their games, their favorite shows and computer interactions, they are presenting themselves to others. The objective of this paper is double. Firstly, I aim to present a characterization of the media addressed specifically to children in order to identify continuities, stereotypes, differences and basic characteristics. The key concept in this phase is the one of representation. Secondly, I work with the interviews that I made during 2012 to thirty children who were between six and ten, inhabitants of the City of Buenos Aires, Argentina. The objective was to listen to children and the meanings the built around their everyday lives. Play and games were approached not only as meaningful cultural practices but also as a way of analyzing the productions that children made from the available discourses in their everyday lives. Desires, preferences and games as children name them are going to be the organizers of the second part of the paper. The relationship between children, media and play is complex, but it is a very interesting way to build some knowledge about the contemporary culture and the ways through which children establish different relationships with it. Both objectives will allow us to build a complex approach to children, media and play in the communicative ecosystem in which they are growing.

Keywords: media, children, play, practices, representations, Argentina, globalization

duekcarolina@gmail.com 


\section{Introduction}

The relationship between media and play has been the subject of my research during the last ten years. Along that period, the research has obtained a common conclusion: children are related to media as consumers, as audiences, as producers and as reproducers of what is shown to them. From the moment in which children are born a new ecosystem composed by different screens and devices becomes their home. Computers, mobile phones, music players, tablets, game consoles: all are part of their everyday lives. It is not necessary to have a tablet or a smart phone to know everything about them. The market, using advertising as an ally, guarantees that any child who is in front of a television screen every single day of his/her life will know what is on, what should be desired, demanded and, finally, bought (with the help of an adult who will pay for that item, obviously). When we reflect upon media and children we need to include the role of the adults who are related, in different ways, with children (parents, teachers, educators among other possible roles); the role of advertising and last but not least: playing. I will argue that playing is a key dimension to analyze contemporary childhoods and their relationship to media culture. When children talk about their games, their favorite shows and computer interactions (Facebook, Specific Web pages) they are presenting themselves to others (Goffman, 1974). Choices, preferences and dislikes seem to be, in the word of children, a way of portraying their identities.

The objective of this paper is double. Firstly, I aim to present a characterization of the media addressed specifically to children (including videogames, apps and television shows) in order to identify continuities, stereotypes, differences and basic characteristics. Global networks such as Cartoon Network, Nickelodeon, Disney and Discovery Kids organize their programming schedule according to a series of objectives, ideas and interests. I will analyze them in order to answer the question about the types of children that these networks "imagine" their audiences are formed by. The key concept in this phase will be the one of representation: the political operation through which the world and everything that happens in it is constructed and shown according to a specific question and a specific point of view (Giroux, 1996).

Secondly, I will analyze fragments of the interviews that I made during 2012 to thirty children who were between six and ten, inhabitants of the City of Buenos Aires. The interviewees needed to have at least a brother or sister, a 
television and a computer at home. The aim of these conditions was to build a sample that could be both homogeneous and coherent. To achieve that objective I used snowball sampling methodology so that I could compose a universe within the children that were interviewed (see Stake, 2005; Patton, 1990; Denzin and Lincoln, 2003 among many others).

The interviews were made in the children's bedrooms with at least one friend to share the interview with. This was an interesting way to not only listen to their statements but also to see the ways in which they talked, corrected and teased each other. The objective of the interview was related to the media ecosystem that I have already mentioned: the knowledge of the devices available in the market, their relationship to television, computers, and mobile phones, to partners and to adults. The objective of the interviews was to analyze the ways in which children described and identified their practices and preferences. Listening to what they had to say enriched our analysis and included their words and discourses about their everyday lives and the ways through which they got in touch with what media and the market had to offer them. All the questions and queries were organized by the games they played: through the descriptions of their games, preferences and social interactions with peers and adults, I found a very rich ground in which to reflect upon media, children and play as a dynamic but solid relationship. Play and games were approached not only as meaningful cultural practices but also as a way of analyzing the productions that children made from the available discourses in their everyday lives (Zires, 1983). Desires, preferences and games as children name them are going to be the organizers of the second part of the paper.

Above the two mentioned objectives lies the global one: to describe the spaces and the ways in which children interact with new media and devices in a complex ecosystem. Martín-Barbero (2003) describes it as a "communicative ecosystem" because of the coexistence of different ways of communication and interaction. The role of TV shows and how they represent children, the place occupied by Facebook and the negotiations with adults have one thing that connects them all: games. Children say that, undoubtedly, playing games is their most favorite activity. On a tablet, a game console, a mobile phone, a computer, a social network, a board game with cards; games seem to link all different dimensions of the everyday lives of contemporary urban children. 


\section{Representing children, constructing global childhoods}

The presence of global media conglomerates in the everyday lives of children is a fact: a great part of urban population is able, not only, to identify Disney and Nickelodeon logos but also the programmes they present and the schedule in which they are organized. This might seem natural, evident and contemporary, but it is not. Major media conglomerates have the power to crystallize what media scholars have called "representation". Representation is, probably, the most important concept when analyzing media and its associate products (Hall, 1981). To represent is to put something in the place of something else. That is, representing is a political action that involves a series of decisions made by the producers that end up configuring the final product in a way and not in another (Giroux, 1996). To represent is to select, cut, choose a point of view, decide where to film or capture a scene; representing is not an innocent process.

The first part of this paper will present an analysis of the ways through which global media conglomerates represent children and, in the same path, the actions, practices and spaces in which children appear in different television programmes, web pages and different media products. The power of discourse, its repetition and redundancy contributes to the construction of an abstract but powerful image of children that is established on a global basis every single day of our lives (Buckingham, 2011; Schoor, 2006). Clearly, an analysis and a discussion about media representation of children are needed: What are the characteristics that represented children have? What do they do? Which are the models, stereotypes and behaviors that seem to be "accepted" and which are not? In sum, how do media build a hegemonic image of contemporary childhoods on a global scale?

Three programmes for kids are here used to illustrate how media both represent and construct contemporary childhood: "Doc McStuffins" (Disney Junior); "Dora, The explorer" (Nickelodeon); and "Special Agent Oso" (Disney Junior). These different TV programmes are representative not only of the television offer but also of the related web pages, games and merchandising. 
Doctors and autonomy in a perfect world: individual games and limited interactions

Television is still the most important source of contemporary representations about the everyday life, although it seems to be displaced more and more by new media, new devices and an increasing personalization of the offer (audiences tend to download or save their favorites programmes to be watched whenever and wherever they prefer to instead of waiting for the scheduled episode of the show). Because smart phones, internet, game consoles, tablets, DVD, mp3 players also produce desires, purchases and new behaviors, we also have to analyze these devices which occupy a great space in the media ecosystem.

Let's follow an example: "Doc McStuffins", the brand new Disney Junior show. The show is about a 5-6 year-old girl who uses an apron so as to pretend she is a doctor. She has a little house in the back yard where she has her "practice". Every time she enters the little house, all the toys become "alive" (the opposite from "Toy Story" films where toys "come alive" when they are alone). She receives "patients" and she "cures" them every single time. The patients are toys from her friends and, in the process of fixing them, she gives children advice about hygiene, germs and diseases. Naturally, "Doc" is able to fix everything she receives. The actual doctor of the family is her mother; her father seems to be a stay-at-home dad (there are no hints that might lead us to think that he works). The relationship between "Doc" and her mother is like colleagues: The mother calls her daughter "doc", the little girl asks about special cases, interesting patients of the day and is always offering a second opinion on her mother's patients (even though her mother never accepts her offers). "Doc" knows mobile phones, how to use a computer and she has the available knowledge when needed. Technology seems to be a natural part of the programme. "Doc" is an independent little girl who can fix everything that is given to her... even her friends call her "Doc".

In this major role play game, it is worth noting that "Doc" works alone in the little house. She has toys as assistants but no friends to share her secret with. "Doc" is a kind of "savior" for her friends when they need her. The rest of the time, she plays alone in her little house. Not even her parents are invited to enter.

This new Disney Junior show is a synthesis of all the major hegemonic representation operations that are identifiable in contemporary television for 
kids. But as it is the last show that Disney presented, the example gets more and more interesting because of its continuities with previous programmes. The example was chosen as a condensation of the offer to which children are related on a daily basis.

Which are the hegemonic representations about children in global television? Parents are present as a secondary subject in the lives of their children. They participate only when children decide them to. Children are autonomous and make their own decisions according to their preferences (for example in "The Backyardigans", Discovery Kids). Their everyday life as represented by media seems to have no conflicts (or at least no important ones) or to present solutions to possible "problems". "Special Agent Oso" (Disney Junior) is probably the most suitable show as in every single episode an objective is achieved or a problem solved by using "three special steps".

This relatively new dimension regarding television for children is what I called "hyper-pedagogization" (Duek, 2011). This concept was identified analyzing the most popular TV shows for children: in all there was "something" useful or interesting to learn. The programmes began to teach children new habits, facts, expected behaviors. The most impressive illustration is "Lazy Town": the show is all about convincing children about the benefits of healthy food, staying fit and practicing sports. The webpage of the programme includes healthy tips to improve the ways children eat, advice to parents, "games" in and through which where children learn how to classify food, and leisure activities according to nutritional properties. There is also a manifesto regarding things the programme likes to encourage, and its sustained causes and initiatives.

The idea of hyper-pedagogization is to condense the new tendency in other media (apps; internet pages related to the shows), presenting them as new spaces of education. The strategy has a double implication: parents tend to allow kids to watch positive and educational programmes more and more; consequently, children are allowed to watch more television as its content is "useful", "good" and "positive".

In sum, autonomy from the adult world, individualism and educational content seem to be the most common characteristics related to children in major media products. These qualities are repeated in advertisements such as "You know what you want, ask for it" (Barbie dolls advertising campaign in 2011), in games and in merchandise related to media products. 
"Doc McStuffins" allows us to enter into the universe of media products addressed to children and to identify a specific way in which contemporary play is portrayed by media: "Doc", as said, plays alone in her little house. She is surrounded by objects, she owns them and she is able to fix and "heal" every single defective toy she receives. Even though she has friends and sometimes plays with them, the key moment happens when she is alone with her toys. The role that play occupies in the show is central: everything is made "as if" Doc were playing with her toys. Even the ways she acts as a doctor are strictly related to mimicry games (Caillois, 1967; Huizinga, 1938). However, here playing is not a way of encouraging imagination and creativity when using toys; everything is used as a channel to incorporate hygiene habits, socially expected behaviors and different ways of interacting with adults and peers. The programme is teaching children habits through the representation of mimicry games that appear as media to incorporate socially relevant information (at least the type of information that a socially adapted child needs to know and use).

In addition, the hero knows a lot about germs and bacteria so, while playing and "healing" patients, she asks an imaginary audience what they should do to kill germs, providing two options. All the episodes end with the repetition of the hygienic suggestion of the day. Everybody is cured, everybody is happy; there is no conflict in a perfect world of perfectly healthy and smiling children.

\section{New practices? Games, consoles and television}

Children are not only autonomous, happy, independent and able to solve situations and fix objects; they are also tolerant in an integrated society. We see this quality in "Handy Manny", on Disney Junior. Manuel Delgado, Manny, is a handyman from México who lives in a small town in the United States of America. He owns a small shop where he receives the calls of the neighbours in order to contract him to repair, fix or build something. Manny does not work alone: he has a team of living and speaking tools; altogether, they succeed in the reparations and never get paid: "we are ok with a thank you". The idea of team work is, here, different from "Doc McStuffins". Manny, a Latino boy, alternates English and Spanish showing his bilingual ability, and teaching audiences different words in a second language (in Argentina Manny's second language is English; in the United States is Spanish). Following the tradition of "Dora the explorer" and "Go, Diego, go" (both on Nickelodeon), Manny represents 
the integration of the immigrant as both harmonic and natural, although it is known how difficult is for Latino people to be included in the American society. Discrimination, tensions and exclusion are the most common situations that migrants in the United Stated have to deal with. It is not casual that Manny is a Latino man who not only is harmonically included but who works peacefully in a foreign country. His migrant condition is a justifier of the way he speaks: Spanglish, a mixture between his native language and the adopted one.

"Dora the explorer", one of the most productive TV shows for analysing the relationship between children and play, is the first cartoon to include the dynamics of the computer on television. We can say that the programme is a hybrid product between television and computer games. Each episode presents an objective: Dora needs to rescue a pet or find someone and it is necessary to go through three different places, for example, forest, mountain, and garden. In order to "help" Dora, there is a pointer (like the computer mouse)) that "asks" audiences where to go. The construction is similar to the videogame. In fact, the videogame "Dora, The explorer" for Wii consoles is similar to the television show. We can be watching television and thinking we are playing a videogame and vice versa.

However, the type of game is a very passive one. We are answering questions but there is an intention to pretend we are clicking and playing Dora's game. The same happens in the Wii Game: there is not much to do but to follow Dora's path to achieve the same objective as in the television show. The only thing the player needs to do is to move the control towards the direction where Dora is heading. A minimum amount of action is included, as if the player would be watching television. The games in the franchise seem to continue the TV content and the toys and accessories do exactly the same. The blend between television and computer languages and structures appear as a new (and effective) combination of two different spaces bonded by the same character. The Latino girl comes to teach, to explore and to present words in both Spanish and English for children to listen. Children watch Dora and producers seem to promise parents that they are going to learn words in Spanish or English according to the country from which it is received.

Hence, to be a spectator and to play in Dora seem to be almost the same thing. To play as a spectator seems to be a new tendency for children's games in new game consoles. The action of playing and the position the spectator oc- 
cupies seem to build an oxymoron, the association of two previously irreconcilable terms. Passivity, automaticity and stillness seem to be the three key words to analyze the new media and the new games addressed to children ${ }^{2}$. Interfaces are more and more complex, actions needed to play or to follow a programme are fewer. Children seem to be considered as "lazy" audiences; at least, the number of actions children have to perform is more and more reduced: producers need them to demand things from their shows, either products or characters but what they offer is a standardized, redundant and predictable show, episode after episode.

"Dora, the explorer" is the most successful merchandise brand with "Cars" (The Disney-Pixar movie). Dora's merchandise is sold all around the world in bags, pencils, clothes, mugs, games, cards, stamps and food. It is almost everywhere if they live in a connected household. This way we find a new major process on a global scale: the production of programmes, products and merchandise for children began to be presented as a system. With the diversification of the offer for children, the only way to build a "loyal" audience is to engage it from different points of view and from different platforms, devices and supports. The construction of a system of programmes and products seems to be the way to have a loyal audience.

The most recent inclusion on this system is console and on-line games. The reach of the cultural industry identified by Adorno and Horkheimer (1969) in our contemporary societies has overcome any prediction. Cultural products in general and for children in particular need to be organized in a system to confront the diversification of the offer. Multi-tasking and multi-platform children are being trained by the contemporary cultural industry. Playing and watching television seem to be thought as two close activities: games, toys, and merchandise appear as a continuity of the television programmes in new supports and devices. This seems to be the key transformation of television in the era of multiple devices and gadgets (Duek, 2013).

\footnotetext{
2 These key words were also identified during the research that included console games as varied supports from where television programmes continue contents presented in different media: "Phineas and Ferb"; "Club Penguin", "Toy Story mania" and "Disney Princess. Enchanted journey", to name only a few representative ones (Duek, 2012).
} 


\section{Training to become adapted citizens: medals and honour to educate children}

The last television programme chosen to illustrate how children are represented is "Special Agent Oso" (Disney Junior). The point of the show is to learn how to do a specific task... with a twist: Oso is a trainee in a never mentioned organization that works as an army or something similar. He needs to accomplish a mission in each episode but he fails inevitably. Then, a kid needs his help to do something: wash the dishes, tie his/her shoelaces, and off he goes. There is an operator that guides Oso and gives him "three special steps" to help the kid. In each episode Oso gets the key to accomplish his own mission while helping others. So, in the end, everybody is happy. Oso gets a medal each time the episode ends and he says "I couldn't have done it without you". The key aspect is the mutual help.

However, there is a twist: the idea of "training exercises" and the hierarchy that is shown (Oso occupies the least important place in the "company") is a replica of the military structure. There is a "mission" and there is someone who needs help. The "difficulties" that Oso helps to overcome are related to the everyday lives of children but especially to the ways a child should behave and the things he/she should do to satisfy adults. For example, a boy wants to help his mother by doing the dishes so he needs help from Oso. He comes, they manage to wash everything and his mother is both proud and grateful of his son and his "special helper". The action is presented as a game but with a certain degree of responsibility: the child needs to accomplish the goal on time to avoid consequences. That is why, when the episode is about to end, a chronometer appears in order to establish the time the child has to end the task.

Here we find, again, the idea of the hyper-pedagogization: children learn to do things while they play and "have fun". The construction of "fun" is polemic as it tends to be related to media and educational content. In video games related to Disney Jr. shows and Cartoon Network there is always an objective clearly identified with school content as an organizer of the game (see, for example, "Disney creates" on the official web site: a "game" in which children are said to be designing their games when they are actually choosing from a pre-established number of options).

The medal that Oso is given in the end is also related to the army actions and gratifications. The homologies between the show and the army are impres- 
sive. The idea of giving a reward to someone because of the accomplishment of a mission established by somebody else is related to subordination and obedience. Oso always does what he is told. He has to do everything he is asked as a trainee. The kids that he helps also need to fulfill their expectations on their own missions. The common factor is the adaptation to the social expectations: to wash the dishes, to get dressed, to cook, to set the table correctly, among many other examples. The message is structured to reward those who do whatever they have to in order to be good kids, good citizens, good role models for the audiences that are watching them.

The children that are represented in "Special Agent: Oso" are the ones that school and parents dream about. They never argue about anything, with Oso's help they achieve their goals, they accept the challenges happily, the demands from the adult world. These kids know what they want and their preferences but they carry the weight of the social demands on their shoulders. The crystallization of the social expectations and the hierarchies are shown in the programme pretty clearly. Obedience is the horizon and the limit of the show. That is what the sitting children at home should get from the programme.

So far, we introduced characteristics of representations about children that major media and networks present every day on different platforms and devices. Children who are autonomous and obedient; who know what they should do and what they want; who follow an educational television show and play the related games on-line and on mobile phones. We identified a system constructed to generate loyalties from the young audiences.

We will now present the testimonies of interviewed children. The objective of capturing their words is to get their own representation about the adult world, the media system, the desires and the games. Identifying the distance between the represented children in global media and the "real" children in Argentina is the key aspect of the second part of this paper.

\section{Representations of represented children: media and the everyday lives of children in Argentina}

In order to complete the previous analysis, it is time to look at children's voices, preferences, opinions and practices. Their voices will allow us to articulate the ways in which children are represented by the media and the presentation they make of their lives and preferences in front of a peer and of an 
interviewer (Livingstone, 1998; James and Prout, 1997). The methodological decision of interviewing children does not mean that the research equaled children to adults: we consider children as subjects, meaning they have their own social, cultural and economic trajectories that configure their lives in one way and not in another (see Bourdieu, 1998; Williams, 1997).

The interviews were made the interviewee's rooms, that is, we sat on the floor and spoke to children in their own space. We asked them to choose one or two friends to share the interview with. Both were methodological decisions taken after a pilot study in 2009 (Duek, 2009). Talking with an unfamiliar adult is more difficult than doing it with a friend on their side. The interviews were open and followed a line of questions and interests. The use of a recorder was explained to children and located in between them. Every interview started asking the activities of that day, for building a relaxed and positive space for children to speak (Corsaro, 2005).

Providing children with space to express themselves is also related to the belief that the exchange between the researcher and the subjects built a new type of knowledge (Foucault, 1996), that we are going to use in order to analyze the interviews. We cared on what children said and how they did it in the specific (and artificial) context of the interview.

As this paper aims to answer the questions about the existence of new practices in a new media ecosystem, the analysis of the interviews cover the relationship with television as well as the use of technology and electronic devices. These aspects will be articulated with the identification of children's representation in global media. This articulation allows us to identify the distance between the represented and the representation; between the construction and children as social subjects.

\section{Television, still a member of the family?}

The informants, thirty boys and girls from six to ten, referred to television as a minor presence in their lives. However, they did it in an interesting way:

Ah... yes... of course I watch TV... it's on all time while I use the computer (Camila, 8 years old)

[my parents] allow me to watch a lot of TV (...) No, with TV there is no problem. Any day I get home and before I prepare myselffor the afternoon, I turn on the TV (Diego, 7 years old) 
These extracts are a synthesis of the gathered testimonies: television is considered as a presence but not a special one. It is always turned on, parents do not say anything about it: the tensions around television and children appear displaced. Children affirmed that there were no time limits with television and that their parents were ok with them watching a great number of hours. To a neutral observer, this might seem obvious but to media analysts, the lack of tension around television and children is a new process: What happened from the very beginning of television until contemporary times?

The answer would demand a long explanation about media, history and material and symbolic conditions of life. Regarding this paper, it is possible to say that, in the context of media expansion and of the multiplication of electronic devices from which people can receive media messages and be in touch with other subjects, television became less a problem than a "friend". The appearance of a new device or technology is unsettling for the societies that receive it (Williams, 1997; Fidler, 1988). The effects are unknown and, until the process and the reception are clarified, there is a gap that needs to be filled with both subjective experience and analytical approaches. There is a moment in which nobody knows much about how a device or a new media is going to enter social practices and representations. This happened with television (Varela, 2005): both audiences and analysts did not (and could not) know what was going to happen with that new presence that included the massive articulation of sound and image.

Nowadays, with smart phones, internet, game consoles and tablets, television seems to be like an old aunt: people tend to cherish her but the practices around it have drastically changed. Audiences download shows they like and choose where, when and in which circumstances they watch them. Access to online media content has changed not only practices but also the ways in which audiences get engaged (or not) with the products they offer (Duek, 2012).

The change found in recent interviews was related to the place that children gave to television in their everyday lives. All the interviewees watched television, without exceptions (a girl whose father did not own a television at home learnt how to watch television on line was she was seven years old... she narrated that proudly). For all, television was part of the household, perhaps not the most interesting or relevant one. 
A first conclusion is that they took television for granted: they seem not to care about it because they knew it was there for them. Television is such a "natural" part of their lives that its presence seems to be underestimated. Even parents stopped limiting the time children were allowed to watch television per day. A second conclusion is that television is no longer a problem for both parents and children. This can be explained by the already mentioned hyperpedagogization, that is, the extension of "educational" and "positive" content that television for children began to present in the last decade. How could someone say "no" to a kid who wants to watch a show about good values?

The possible first conclusion is sustained by children's testimonies: television is a friend, is a non-problematic presence that can be turned on in the exact same moment in which children enter their houses. In contemporary times, television is not a social problem. It is, of course, still the most powerful producer of social representations, images about societies and expected behaviour, of actions that are or should be socially condemned (Hall, 1981; Lazarsfeld and Merton, 1948, among many others).

Following Winnicott's definition of transitional objects, Silverstone (1994) affirms that television tends to occupy the space left by blankets and teddy bears. Television would work as a transitional object and would occupy a crucial place in the everyday lives of children as a part of the family. However, there has been a displacement in what children say about television. Not only is television "taken for granted"; it is also almost, and paradoxically, invisible. Not because children do not watch what it is on, but because it began to work as the contemporary radio: it is turned on and continues to be like that all day long.

"I always watch TV... actually, TV is always on... sometimes I sit down and pay attention... but not much" (Camila, 9)

\section{"I have a computer and a TV in my room and nobody gets to enter. I do what- ever I want" (Pablo, 7)}

The positions in which television is received are not new. Many years ago, Stuart Hall (1979) defined three decoding positions to analyze the ways through which the audiences received media messages: the oppositional, the negotiated and the dominant or hegemonic. These positions would explain three general tendencies in the encoding-decoding process. We have now a possible fourth general decoding position: the random one. We cannot say that audiences are 
disengaged from television but there is a distance according to what informants are saying that would indicate a great distance between the television set and their attention. It is indeed very interesting to identify audiences that can be both present/absent in front of a television set: they choose but they decide when to pay attention to it. There is a continuum in which children claim they are major participants in what they do with television.

The idea of an autonomous child appears here in the same way as in the previous analysis: children present their choices and decisions as a way of presenting themselves. They can do whatever they want as they own a television in their rooms or they can be with the computer not paying attention at all to what is on television... but they seem to be unable to decide to turn it off. And that can be easily explained by the idea of television as a member of the family: a cherished one but not the most important member of the household.

Children watch television, clearly, but the TV's place in their speech is secondary. Television is not an interactive device, does not allow feedback nor interactivity; television is not a device to play with. That is why merchandise and associated products appear with a great relevance: they complement the impossibility that television seems to have to be present in new devices and electronic gadgets. There is clearly a special place for the potential "new members of the family". That will be the key of the following paragraphs.

\section{Facebook and me: negotiations, struggles and victories (games and more games)}

If television is a naturalized member of children's everyday lives, computers appear to be the most desired, cherished, valued and fascinating objects for children, followed by mobile phones. This is clearly related to the hegemonic representations not only of children but also of their behaviour and preferences. Along the research, Facebook was mentioned by children as a desired space to "conquer". Facebook was characterized as the major space of family struggle: children want an account; parents do not allow them to. There are two important facts to include: firstly, Facebook is supposed to be for children over 13, but it only takes a fake birth date to get access to a personal account; secondly: "fear" appears to be the most important reason for parents to deny the possibility of a personal Facebook account. Parents were afraid of the exposition an account entails, of the consequences of children's posts, of the fake age.... 
It is understandable that negotiations began in all the families of the children interviewed. Some children argued that they were going to behave properly and accepted being friends with their parents in order to encourage control from adults. The most important thing was to have a personal account in order to use it as they like it.

"I decided to have my own Facebook account [he used to play Facebook games with his father account] when I heard that a friend of mine was allowed to. His mother is really overprotective. It was very strange for him to have one and not me. I realized that it is very fun and I do spend a lot of time connected" (Raphael, 10).

"I asked my parents if I could have two Facebook accounts and they said yes (...) When I ran out of lives in one account, I can use the other one to continue playing” (Zoe, 7).

In these two extracts we find different strategies. The two most important reasons why our informants opened a Facebook account were "the games" and "my friends had an account"; that is, Facebook is considered as a space for playing on line games and to continue social tendencies of the peer groups. Interestingly, a few informants mentioned the chat rooms and the wall as key spaces; most children affirmed that Facebook was, for them, almost a synonym of online gaming. "Pet Society" and "Pet city" were the two most mentioned games. The informants said they liked playing several games but that they preferred these two.

In both games, the key is to protect and feed a pet. In order to have money and coins to dress them, build them houses and everything, different objectives and games appear to collect "money". With that money, players can improve the lives of their pets. But there is (always) a twist: the life quality of the pets and the objects they own appear in a ranking shared with other players of the same game. This is a quality of Facebook games: in every single game, there is a ranking between the "friends" of the user who are playing it. The game announces when someone bet a friend's score and makes it public to the rest of the "friends".

The logic of exhibitionism in Facebook games is complemented with competition. Some informants claimed that they preferred Facebook games as they 
can know who they bet or who bet them in the rankings. This generation was not only born with television, it is also a generation that is used to the victories and defeats in live shows broadcasted globally.

Facebook is presented as a social network, like others. The definition of the "social" dimension of the networks occurs in a context where technology, access, exhibitionism and competition, are both complex and dynamic. Technological communications and interactions do not replace face to face sociability but the gathered testimonies suggest a tendency to follow the peers' activities so as to continue belonging to the groups. Sociability continues to be the most relevant and pertinent explanation to major social behaviours. A parent told us after his son was interviewed:

"I let him have the account as it had begun to be such a great desire for my son that saying no only increased his effort to convince me. I said yes, but he has to be my friend and I am controlling him all the time. It is so scary to leave him alone in such a complex social network... I do not know... all his friends have an account... it is difficult..." (George, 45, father of Robert, 8).

As mentioned, fear and social pressure are two reasons why this father allowed his child to open an account. The parent was evidently doubtful but he identified the ways in which his negative increased the child's desires. The forbidden thing becomes the most desired one. This is a process the market knows how to use in order to attract consumers, followers and users.

The same process can be identified with mobile phones. On one side, insecurity in Argentina seems to be a great reason for parents buy a mobile phone that children take to school. That led to great problems for educational institutions: should they allow or encourage mobile phones in the classrooms or should they forbid them? The answers are still being processed by institutions. Meanwhile, each school presents its own set of rules (some schools demand students to leave their mobiles in the offices when they enter the institution and they can collect them in their way out). On the other side, major mobile phones companies have presented campaigns attracting children as users. "My first Claro" was the most important advertising campaign in which different strategies to convince parents were shown. Insecurity and advertising are two fundamental actors to understand why in a country of 42 million inhabitants, 52 million of mobile phones are connected. 
When interviewed, children mentioned mobile phones, personal computers and game consoles as objects they wanted to have in the near future. The relationship between children and Facebook seems to synthesize the tensions around the new technologies of information and communication and the necessary negotiation between children and adults. Desires, sociability and trends are three key words to analyze the place that new devices occupy in the desires of contemporary middle-class children in Argentina and, perhaps, in the world. The role of the market is a very important one when analyzing the desires that children build around new objects and technologies: the youngest, the better, for the capitalist market. If children grow up with a strong desire to own what the market has to offer, there is a great possibility that the adults-to-be will be active consumers (according to their economic possibilities, naturally).

\section{Conclusion: media, children and play}

At the beginning of this paper two objectives were mentioned: the description and characterization of the hegemonic representation of children built by major global media and the analysis of what children said about media and play in their everyday lives in interviews that were made to them.

The first part identified children being represented as autonomous subjects who knew what they wanted and the ways through which the transformation of television discourse to an educational and "positive" content transformed it in a very "friendly" media at home: educational content, suggestions of politically correct social behaviour and tips about personal hygiene were combined in programmes that present themselves as a continuity of school and family as two great institutions with which children establish daily relationships.

The second part presented a brief analysis of interviews made to boys and girls from six to ten. Television was identified as a member of the family, "taken for granted". We identified a potential fourth kind of decodification, the "random watching", that would imply different moments and degrees of attention between children and television, which is always turned on. The space of desires, expectations and struggle was related to new technologies and, especially, to Facebook as a social network where games and sociability are strategically combined. Advertising and sociability perform a great influence on children. The struggles that children narrated when trying to convince parents to open 
their Facebook accounts are clearly articulated with the representations of children that major global television companies pursue twenty four hours a day.

At the end of these two analysis and reflections I want to present a new question that may encourage further research: are computers and other new devices the new "problematic" consumptions that parents are trying to control or is there a (kind of) harmonic incorporation of new media and technologies in the everyday lives of children around the globe? If television ceased to be "the problem" parents had to limit, what roles are parents assuming in this new and complex media ecosystem?

The answer demands new research but something can be affirmed: children are represented in the media and present themselves to others using very similar strategies. Media, children and play are three major dimensions of the everyday lives of children. The ways in which they are related to contemporary culture and to the available discourses with which children coexist. We found that play can be analyzed as the link between different media: even though play is sometimes an "excuse" to engage children in different supports and through varied devices, play unites all the new media and gadgets available in the market. Children play in Facebook, in the computer, in tablets and in game consoles. Play is a great organizer of contemporary childhoods and it is used by global companies as a way of continuing the relationship with special characters in different spaces (the market, new technologies, among others).

But also, autonomy and education seem to be key words to approach both the represented and the representation. Once again, analyzing representations is not only a methodological tool but a political contribution to society as reading and deconstructing representations is the first step to assume an active role as audiences. That is, probably, the great first step both children and adults should give with the aid of educational institutions. 


\section{References}

Adorno, T. \& Horkheimer, M. (1969). Dialéctica del iluminismo. Buenos Aires: Sur.

Bourdieu, P. (1998). La distinción. Criterio y bases sociales del gusto. Madrid: Taurus.

Buckingham, D. (2011). The Material Child. Growing up in Consumer Culture, London: Polity Press.

Caillois, R. (1967/1994) Los juegos y los hombres. La máscara y el vértigo. , México: FCE.

Corsaro, W. (2005). Collective Action and Agency in Young Children's Peer Cultures. In Qvortrup, J. (ed.), Studies in Modern Childhood: Society, Agency and Culture. Basingstok: Palgrave Macmillan.

Denzin, N. \& Lincoln, Y. (2003). Strategies of Qualitative Inquiry. New Delhi and Londres: Sage and Thousand Oaks.

Duek, C. (2009). Memoria, televisión y juego infantil. In Mangone, C. (ed), Cuadernos Críticos de Comunicación y Cultura No5, volume 1 diciembre 2009- marzo 2010, Bueno Aires, pp. 20-31.

Duek, C. (2011). Infancias globales, infancias locales. La televisión y la representación de los más chicos. En Entel, A. (comp.), Infancias de Latinoamérica. Un cuadro de situación, Buenos Aires : Fundación Walter Benjamin, Fundación Arcor,

Duek, C. (2012). El juego y los medios. Autitos, muñecas, televisión y consolas. Buenos Aires: Prometeo Libros.

Duek, C. (2013). Infancias entre pantallas. Buenos Aires: Capital Intelectual.

Fidler, R. (1988). Mediamorfosis. Buenos Aires: Granica.

Foucault, M. (1996). La verdad y las formas jurídicas. Barcelona: Gedisa.

Giroux, H. (1996). Placeres inquietantes. Barcelona: Paidós.

Goffman, E. (1974). Frame Analysis. Boston: Northeastern University Press. 
Hall, S. (1979). Encodificar/decodificar. In Hall, S. (comp), Teorías de la Comunicación. Buenos Aires: Fundación Hernandarias.

Hall, S. (1981). La cultura, los medios de comunicación y el efecto ideológico. In Curran, J. (comp.), Sociedad y comunicaciones de masas. México: FCE.

Huizinga, J. (1938). Homo Ludens. Buenos Aires: Emecé.

James, A. \& Prout, A. (1997). Constructing and Reconstructing Childhood: Contemporary Issues in the Sociological Study of Childhood. London: Routledge.

Lazarsfeld, P. \& Merton, R. (1948/1986). Comunicación de masas, gusto popular y acción social organizada. En M. de Moragas (comp.), Sociología de la Comunicación de masas. Barcelona: Gustavo Gili.

Livingstone, S. (1998). Making Sense of TV-narratives: Children's Readings of a Fairy Tale. [review of I Rydin]. Nordicom information, 20(4), 89-95.

Martín-Barbero, J. (2003). Retos culturales de la comunicación a la educación. Elementos para una reflexión que está por comenzar. En Morduchowicz, R. (comp.), Comunicación, medios y educación. Roxana Octaedro: Barcelona.

Patton, J. (1990) Qualitative Research Design: An Interactive Approach, London: Sage.

Schoor, J. (2006). Nacidos para comprar. Barcelona: Paidós.

Silverstone, R. (1994). Television and Everyday Life. London: Routledge.

Stake, R. (2005). Qualitative Case Studies. In Denzin \& Lincoln, The SAGE Handbook of Qualitative Research. New Delhi and London: Sage and Thousand Oaks.

Varela, M. (2005). La televisión criolla. Desde sus inicios hasta la legada del hombre a la luna 1951-1969. Buenos Aires: Edhasa.

Williams, R. (1997). Marxismo y literatura. Barcelona: Península/Biblos.

Zires, M. (1983). El discurso de la televisión y los juegos infantiles. In Comunicación y cultura $N^{\circ} 10$, voulme 1 México, pp. 1-23. 